\title{
Bird Integumentary Melanins: Biosynthesis, Forms, Function and Evolution
}

\author{
Ismael Galván ${ }^{1}$ and Francisco Solano ${ }^{2, *}$ \\ 1 Department of Evolutionary Ecology, Doñana Biological Station-CSIC, 41092 Sevilla, Spain; \\ galvan@ebd.csic.es \\ 2 Department of Biochemistry and Molecular Biology B \& Immunology, School of Medicine and IMIB, \\ University of Murcia, 30100 Murcia, Spain \\ * Correspondence: psolano@um.es; Tel.: +34-86-888-7194
}

Academic Editor: Manickam Sugumaran

Received: 24 February 2016; Accepted: 30 March 2016; Published: 8 April 2016

\begin{abstract}
Melanins are the ubiquitous pigments distributed in nature. They are one of the main pigments responsible for colors in living cells. Birds are among the most diverse animals regarding melanin-based coloration, especially in the plumage, although they also pigment bare parts of the integument. This review is devoted to the main characteristics of bird melanins, including updated views of the formation and nature of melanin granules, whose interest has been raised in the last years for inferring the color of extinct birds and non-avian theropod dinosaurs using resistant fossil feathers. The molecular structure of the two main types of melanin, eumelanin and pheomelanin, and the environmental and genetic factors that regulate avian melanogenesis are also presented, establishing the main relationship between them. Finally, the special functions of melanin in bird feathers are also discussed, emphasizing the aspects more closely related to these animals, such as honest signaling, and the factors that may drive the evolution of pheomelanin and pheomelanin-based color traits, an issue for which birds have been pioneer study models.
\end{abstract}

Keywords: melanogenesis; pheomelanin; eumelanin; avian melanins

\section{Introduction}

Color is one of the traits that most conditions the appearance of animals. Animal coloration is extraordinarily diverse, and this diversity attracted the attention of early scientists and it eventually played an important role in the development of paradigms in biology such as the speciation theory [1]. Indeed, the first attempts to explain the origin of this diversity in colors precede modern studies on evolution and adaptation [2]. Color largely affects the way animals communicate with others by fulfilling functions such as concealment and signaling of genotypic quality to conspecifics, and coloration plays a relevant role in the evolution of animal life histories [3].

Animal coloration is the result of two different but related physical processes: (a) the direct absorption of specific wavelengths of light by natural pigments, which could be termed pigmentary colors; and (b) the interference of light reflected by biological microstructures with contrasting refractive indices, which creates the so-called structural colors. The latter mechanism allows producing colors that cannot be generated by pigments alone, but specialized microstructures often require the presence of pigments that absorb certain wavelengths to produce structural colors [4]. Therefore, pigmentary and structural colors are not the result of two independent processes, but rather pigments are the main basis responsible for the entire diversity of animal coloration.

Among animals, the colors of birds are particularly diverse, which is related to the fact that, contrary to other vertebrates such as mammals but in common to humans, birds mainly rely on visual cues for communication [5]. The pigments responsible for this diversity are deposited in feathers 
and bare parts such as bills and legs. These pigments are, in alphabetical order: carotenoids, flavins, melanins, porphyrins, psittacofulvins, pterins, purines and turacin. Most of these pigments are present in only certain groups of birds. Melanins and carotenoids are widespread among birds and therefore represent the main contribution mechanisms to avian color diversity, but usually melanins are more abundant than carotenoids and in some species, such as barn swallows, the levels of melanin are orders of magnitude greater than carotenoids [6-8].

Melanin is the generic name used to refer to perhaps the most ubiquitous, resistant, heterogeneous and ancient polymer found in nature [9]. As in mammalian skin and hair, the integument of birds contains two chemical forms of melanin: eumelanin, which gives rise to dark black, brown or grey colorations, and pheomelanin, which gives rise to lighter yellowish to reddish colorations. Here, we aim at reviewing the mechanisms by which birds produce melanins and melanin-based color traits, with an emphasis on the implications that these mechanisms have for understanding the evolution of these traits and how pigmentation can constrain different aspects of avian biology.

\section{Cell Biology of Bird Melanization: Avian Melanosomes}

Although melanosomes and melanin granules have been extensively studied in mammals, avian feathers were a good model for the early electron microscopy studies of this subcellular organelle and melanogenesis. It appeared that the avian material offered especially favorable conditions for such studies in comparison to mammalian skin. A single barb or barbule washed in acetone, dried and mounted for examination shows a very thin layer of keratin that is relatively transparent to the electron beam, so that sample preparations were easy for such pioneer studies. Thus, comparison of the microscopic structure of black feathers from the Brown Leghorn male chicken, the brown ones of the female, and Rhode Island red fowl feathers suggested the existence of two types of melanosomes containing two different types of melanin [10].

The granules from the black breast feathers of the Brown Leghorn male consisted of dense ovoids about $1 \mu \mathrm{m}$ long, with a smooth and sharply defined edge and zigzag longitudinal strands. Rhode Island Red feathers showed granules with different structure. They were discoidal, quite uniform in size, less organized, without internal strands and empty vacuoles. White feathers were quite devoid of granules. In sum, these studies highlighted that the change from black to red color was not merely caused by a change in the nature of the pigment-containing granule, but also by changes in the genesis and structure of the granule. These ultrastructure differences between subcellular organelles forming eumelanin and pheomelanin were observed in other avian models, such as melanocytes from regenerating feathers in the pink-eye fowl mutation [11,12].

The incorporation of tyrosinase (the key enzyme for melanogenesis) to premelanosomes was also investigated in regenerating fowl feathers by histochemical staining with dopa [13], showing that coated vesicles were active in the transport of tyrosinase to initiate melanin formation. However, the avian melanin granules were not a good model for further tyrosinase studies, as those granules were mature organelles where most melanin is already formed and tyrosinase is mostly inactive after the previous period of melanin formation in melanosomes at the follicular melanocytes.

Studies on fowl showed that two parallel processes take place in developing feathers: growth caused by keratin deposition, and deposition of melanin. Basal keratinocytes form a ring from which the rachis and barb ridges differentiate. Melanocytes, initially located in the dermal papillae below the keratinocyte ring migrate towards the barb and simultaneously transfer melanin granules to the barbs and barbules of the definitive feather. Similar to mammalian skin and hair, the process of melanin transfer includes the incorporation of single melanosomes or melanosome complexes to the cytoplasm of keratinocytes that are incorporated to the growing feathers. Further studies reported that the pattern of formation and transference of melanosomes in bird feathers showed some differences in comparison to mammalian hair [14], but the detailed mechanism is still not totally clarified.

Recently, it has been proposed that the transfer of melanin from mammalian melanocytes to keratinocytes is carried out by a coupled exocytosis of the "melanocore" of melanosomes, with a 
subsequent endocytosis by keratinocytes rather than a heterophagocytosis of the melanocyte dendrite tip or the release of melanosome-loaded vesicles [15]. By contrast, almost nothing is known about the transfer of melanins from follicular melanocytes to feathers. Lin et al. [16] have emphasized the importance of the avian feather as model for the cellular and molecular studies on the formation of pigment patterns. They found that melanocyte progenitors are distributed as a horizontal ring in the proximal feather follicle, sending melanocytes vertically up into the epithelial cylinder, which gradually emerges as feathers grow. However, how melanins are embedded in the growing keratinized substance of the feather vane might require some specific processes different of the mechanisms of transfer in the melano-epidermic unit.

During the last years a new aspect of interest in avian melanosomes has been originated from studies on fossil feathers because of the possibility of inferring the color of extinct birds and non-avian theropod dinosaurs. Although the term melanosome is widely used in these studies to refer to the fossilized structures, they actually deal with the morphology of fossil melanin granules. The term melanosome would indicate a functional organelle in a melanocyte instead of melanin granules that are pumped out of the organelles to be deposited in feathers. In any case, in these studies it has been assumed that rod shape granules contain eumelanin while spherical, smaller granules contain pheomelanin. Some of these studies (e.g., $[17,18]$ ) base this assumption on previous work on human hair melanin granules that used relatively aggressive treatments to extract melanins from the hair matrix [19]. As pheomelanin granules are less resistant to mechanical stress than eumelanin granules, such treatments might break pheomelanin granules making them appear spherical in contrast to unaltered eumelanin granules. Indeed, they noted that the shape of pheomelanin granules was more heterogeneous than that of eumelanin granules, so both spherical and rod shape granules of pheomelanin were actually observed [19]. Furthermore, a recent study using a slightly less aggressive extraction of melanins has reported rod shape granules from red, pheomelanin-based chicken feathers [20]. Therefore, granule morphology may not be a good predictor of the chemical composition of melanins that they contain, something that should be further explored.

Other studies on fossil feathers have established the average morphology of melanin granules in feathers of extant birds exhibiting different colors (black, brown, grey) to infer the color of fossil feathers on the basis of their morphology [21-24]. However, detailed studies on the color generated by the different chemical forms of melanins are lacking, so a limited variety of colors can be determined from the latter studies. As an additional cautionary note, there is an open discussion about the possibility that these fossilized granules are actually preserved bacteria [25]. In sum, more caution is needed when taking the predictive capacity of melanin granule morphology to make deductions on the integument coloration of extinct birds and dinosaurs.

\section{Feather Melanin Isolation and Methods for Structural Determination}

As mammalian hair, feathers contain two different types of melanin: (a) eumelanin giving a dark black, brown or grey appearances; and (b) pheomelanin, leading to a lighter yellowish to reddish appearances. In most cases, feather melanins are a mixture of eu- and phaeomelanin, although the relative amounts of each pigment differ with the avian species [26]. First isolation protocols involved the use of alkaline conditions to disrupt the hard keratin matrix and release the pigment, but alternative mild protease-treatments can be also used.

The most reliable method for melanin identification and quantification is high performance liquid chromatography (HPLC) analysis of chemical degraded samples [27], and later improvements [28,29]. Feathers are trimmed, washed with water and digested with acidic permanganate or hydriodic acid for eumelanin or pheomelanin analysis respectively. Resulting PTCA (pyrrole-2,3,5-tricarboxylic acid) and AHP (4-amino-3-hydroxyphenylalanine) are used as markers of eumelanin and pheomelanin, respectively, with conversion factors of 50 and 9 when applied to feathers [8,26-28]. Alternative degradation treatment has been later introduced for pheomelanin, based on the alkaline oxidation 
with $\mathrm{H}_{2} \mathrm{O}_{2}$. Under these conditions, quantitated markers are TTCA (thiazole-2,4,5-tricarboxylate) and TDCA (triazole-4,5-dicarboxylate) [29-31].

One of the main difficulties in the melanin analysis is the inability to study melanin structure in unaltered state. To solve this problem and to develop direct methods of melanin analysis, Liu et al. [32] have used synchrotron-based photoionization mass spectrometry (MS) to determine the composition of feather melanins. Roughly, it has been found that brown plumage is related to greater content of benzothiazole units, black plumage to dihydroxyindole oligomers and grey to benzothiazine units. GC/MS has also used for pheomelanin, as it can distinguish benzothiazines from benzothiazoles [33]. Electron paramagnetic resonance (EPR) and X-ray photoelectron spectroscopies have been also applied to explore the properties of eumelanin in silky fowl tissues [34]. Finally, the use of Raman spectroscopy as a simple, non-invasive technique to identify and quantify melanins in feathers and hairs has been recently proposed [35,36]. Raman spectroscopy gets different spectra for eumelanin and pheomelanin without the need of extracting the pigments, and is potentially applicable to any biological tissue.

\section{Melanin Synthesis Pathway with Special Reference to Avian Melanin}

Melanogenesis is not a unique and unaltered biosynthetic pathway, as animals, plants and microorganisms show some differences in the nature of precursors and the enzymatic machinery [9] but all pathways show common features: an initial phase consisting of an enzymatic-catalyzed oxidation of phenolic precursors to quinones, and a second phase consisting of unregulated polymerization of phenols and their related quinones.

The most common and best-known route is called Raper-Mason pathway (Figure 1) [37,38]. Originally, this pathway was established as a route for the synthesis of dark eumelanin. Melanogenesis pathway was later extended $[39,40]$ with a branch from L-dopaquinone leading to pheomelanin (called the Prota-Rorsman pheomelanogenesis branch in honor of these two pioneer researchers of pheomelanin chemistry). Pheomelanin is widely distributed among birds, which is related to the fact that this type of pigment was reported for first time in red feathers and hair [39,41].

In the initial step of melanogenesis, L-tyrosine is oxidized by oxygen in a tyrosinase-catalyzed reaction. Tyrosinase displays a complex mechanism of action [42] with two consecutive different activities: tyrosine hydroxylase and dopa oxidase. Both actions take place consecutively to generate L-dopaquinone (Figure 1). This o-quinone plays a pivotal role in animal melanogenesis [43] leading to eu- or pheomelanin depending on the chemical composition of the solution. L-dopaquinone is highly reactive, able to react with a number of chemical groups including amino, thiol and hydroxy groups. In the classical Raper-Mason pathway, L-dopaquinone undergoes a spontaneous intramolecular cyclization to be converted into L-leukodopachrome (L-cyclodopa) by a nucleophilic attack of its side chain amino group on position 6 of the aromatic ring. The rate of this reaction is highly dependent of $\mathrm{pH}$, as the reactive species for the attack is the neutral amino group $\left(-\mathrm{NH}_{2}\right)$, non-protonated. The $\mathrm{pK}$ of the amino group of L-dopa is approximately 8.7. Accordingly, eumelanogenesis is dependent of the $\mathrm{pH}$ of the media, being inhibited in acidic intramelanosomal media [44].

Following the eumelanogenesis pathway, L-leukodopachrome is an unstable indoline with strong reductant properties, so that it undergoes a spontaneous fast redox reaction with its precursor L-dopaquinone to regenerate half of L-dopa and to yield half L-dopachrome (Figure 1). L-dopachrome is a second pivotal intermediate in the melanogenesis pathway specific of eumelanogenesis [45-47]. L-dopachrome tends to evolve to dihydroxyindoles with a putative decarboxylation, so that two different intermediates can be formed, 5,6-dihydroxyindole (DHI) and -5,6-dihydroxyindole-2-carboxylic acid (DHICA). Actually, mixtures of both indoles appeared, but the ratio depends on several factors, such as $\mathrm{pH}$, presence of metal ions and the action of a specific enzyme, dopachrome tautomerase (Trp2, tyrosinase-related protein 2) [45,48]. In mammals, the main factor is the activity of this enzyme, which has been well studied and characterized. In birds, this activity seems to be quite low and is has been rarely determined [49]. The presence of traces of $\mathrm{Cu}$ (II) 
or $\mathrm{Zn}$ (II) in follicular melanocytes could also favor the transformation of a portion of L-dopachrome into DHICA rather than into DHI.

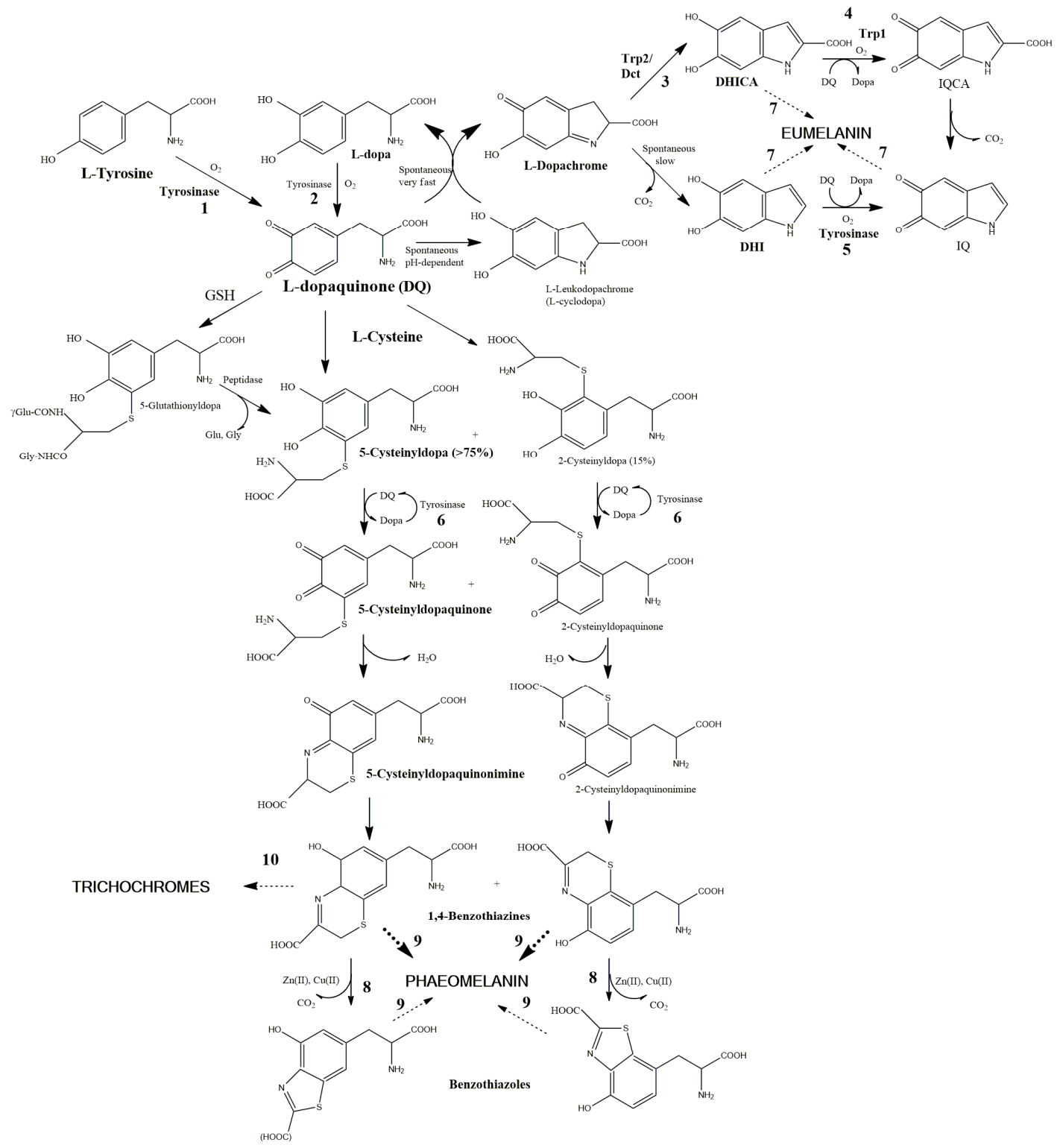

Figure 1. Melanogenesis pathway. L-Ty is oxidized to L-dopaquinone by tyrosinase. L-dopaquinone is a branch point to eumelanogenesis (internal cyclization to indole, the classical Raper-Mason pathway) or pheomelanogenesis (thiol addition on the aromatic ring). Other reactions lead to dark eumelanin (upper part) or yellowish to reddish pheomelanin (lower part). Enzymatic-catalyzed reactions are numbered 1-6, and metal ions L-catalyzed reactions are numbered 7-10, although traces of those metal ions can replace tyrosinase and Trps at reactions 2-6. Reaction 1 is the only key and rate-limiting step of the pathway. Mammalian and avian melanogenesis do not show differences concerning this essential step, but the availability of metal ions to catalyze rearrangements at the final steps may show differences among mammalian skin and avian feathers. See text for other details.

In the final phase of the eumelanin pathway (Figure 1), both DHI and DHICA are putative substrates of tyrosinase or other enzyme involved in the eumelanin synthesis, tyrosinase-related protein (Trp1), to yield the corresponding 5,6-indolquinones [50]. The specificity of tyrosinase and/or Trp1 to the carboxylated or decarboxylated species shows differences between mouse and human [51], but to our knowledge there are no data about the specificity of avian tyrosinase and Trp1. 
Subsequent crosslinking reactions between oxidized forms (5,6-indolequinones) and reduced ones (5,6-dihydroxyindoles) generate the eumelanin pigment.

Returning to the pivotal point of the general melanogenesis pathway, L-dopaquinone proceeds to pheomelanin formation in the presence of L-cysteine or other thiol-containing compounds, such as the antioxidant GSH [40]. This is due to the much faster reaction of L-dopaquinone with thiol groups in comparison to the intramolecular cyclization leading to eumelanin [43,52]. Thus, in the presence of those agents, the thiol addition occurs, especially at acidic $\mathrm{pH}$ found inside pheomelanosomes. The addition of L-cysteine to L-dopaquinone can take place at different positions to yield a mixture of Cys-dopa derivatives, although the main isomer is 5-S-Cys-dopa [53,54] followed by 2-Cys-dopa (Figure 1, middle part) and other di-cysteinyl derivatives. If the thiol is GSH, 5-S-glutathionyl-dopa is predominantly formed, although a peptidase converts this derivative in 5-Cys-dopa by release of glutamate and glycine [40].

Cys-dopa isomers undergo oxidation to Cys-dopaquinones by mechanisms that are only partially known. Tyrosinase might barely catalyze these reactions, as available data indicate that mammalian tyrosinase shows very low affinity to Cys-dopas, making them very poor substrates $[43,55]$. There are no available data about affinity of avian tyrosinase to Cys-dopa. These oxidations have been extensively studied at Naples by Napolitano and d'İschia. However they approach biomimetic conditions at neutral $\mathrm{pH}$ with peroxidase plus hydrogen peroxide or inorganic oxidants, but no avian tyrosinase. Thus, it remains a low possibility that in vivo reactions in avian feathers could proceed under slightly different mechanisms than those described. Under these conditions, Cys-dopas are oxidized to Cys-dopaquinones through an intermediate dehydration to cyclic Cys-o-dopaquinonimines (Figure 1) and then to 1,4-benzothiazines (BTZ) [56,57]. Inside melanocytes, the mechanism for the oxidation of Cys-dopas to Cys-dopaquinones might be the redox reaction with L-dopaquinone that is reverted to L-dopa [43]. Thus, tyrosinase indirectly catalyses the oxidation as shown at Figure 1 although Cys-dopas are not direct substrates.

The formation of carboxylated 2,3-dihydrobenzothiazines (DHBCA) before 1,4-BTZ has also been suggested [58], but a fraction of 1,4-BTZ evolves to related heterocycles, such as benzothiazoles, as significant proportions of these derivatives are detected by degradation of natural and synthetic pheomelanins [59]. Other more conjugated compounds, such as benzothiazolylthiazinodihydroisoquinolines, have been identified during the final polymerization reactions of pheomelanogenesis. These units have not shown at Figure 1 to avoid extra complexity. In some of these oxidative rearrangements, traces of $\mathrm{Zn}(\mathrm{II})[60,61]$ and other ions [62] seem to regulate final reactions (Figure 1). The transformation of benzothiazines to benzothiazoles is a complex organic rearrangement poorly understood that implies decarboxylation of the heterocycle ring [57]. The mixtures of those units yield a pheomelanin polymer containing different proportions of them $[53,63]$. The chemical factors to control a "clean" dimerization of benzothiazines leading to trichochromes against the formation of benzothiazoles and other species leading to pheomelanins remains unknown. $\mathrm{Zn}$ (II) ions seem to be involved in both processes [64]. Although conditions leading to trichochromes or ill-defined pheomelanin should be clarified, there is no doubt that these variations account for the different colors in yellowish to red avian feathers.

\section{Types and Building Blocks in Bird Melanin}

Eumelanin and pheomelanin are present in mammals and birds, and there are no clear differences between both types of animals. However, due to the high diversity in feather coloration, it is likely that pheomelanins are more widely distributed, and maybe more chemically diverse, among birds. Different models help to understand the structural properties of these polymers $[9,29,31,43]$. Briefly, the main building block of eumelanin is DHI. Possible positions for polymerization in this unit are 2, 3,4 and $7[9,29]$. Covalent bonds $4 \rightarrow 7$ are the most abundant cross-link among units, but positions 2 and 3 are also possible. This would give place to a branched and relatively flat polymer. On the other hand, as some of these units are carboxylated (DHICA units), position 2 is blocked, and position 3 is 
mostly inactivated by the electron withdrawing effect. Thus, DHICA tends to link through linear $4 \rightarrow 7$ bonds. The ratio DHI/DHICA in a eumelanin molecule depends on the dopachrome tautomerase activity (Dct) activity and/or the presence of metal ions [46,48]. Units of L-dopa, 5,6-indole quinones or carboxylated pyrrolic units could also be incorporated in low proportion to the polymer during its formation [43].

PTCA (Pyrole-2,3,5-tri carboxylic acid) and PDCA (Pyrrole-2,3-di) were established as the classical markers of DHICA and DHI units in eumelanin after chemical degradation of eumelanin. More recently, PTeCA (pyrrole-2,3,4,5-tetracarboxylic acid) and isoPTCA (pyrrole-2,3,4-tricarboxylic acid) have also been detected in very old melanin ink sacs [31,43], suggesting extra cross-linking of DHI units during the aging of the eumelanin polymer. PTeCA/PTCA ratio has been suggested as a good indicator of eumelanin aging. According to that aging process, it has been proposed that the size of the mature eumelanin molecules is large due to the complex mixture of different dihydroxyindole intermediates and the possible cross-linking among those units. Recently-formed pigment molecules, especially from DHICA, can be formed by small oligomers, such as dimers, trimers and tetramers $[29,30]$.

On the other hand, it has proposed that eumelanin is comprised at least partially of non-covalent supramolecular aggregates formed by self-aggregation of L-dopa [65]. The monomers would be linked together by a combination of hydrogen bonds, $\pi-\pi$ stacking, and ionic bonds. This report suggests that unmodified L-dopa may be part of the building blocks for eumelanin, but it needs confirmation, as it implies that tyrosinase would not be the rate-limiting step of the pathway, as L-dopa would be incorporated to the melanin polymer without oxidation.

Pheomelanin is more treatable than eumelanin, as it is more soluble than eumelanin due to its lower degree of conjugation [66]. Most of this pigment can be dissolved in alkali or acid media and it consists of oligomers formed by sulfur-containing units, mostly benzothiazine and benzothiazole (see Figure 1). More conjugated complex units such as benzothiazolylthiazinodihydroisoquinoline rings have been proposed in the pheomelanin structure [61].

In addition to eu- and pheomelanins, some reviews on avian pigments [67] consider two extra minor types of avian melanins, termed trichosiderins and erythromelanins. The term trichosiderin is equivalent to trichochrome, which is the recommended term [41]. Trichochromes are dimers of benzothiazines, so that they should be considered a particular type of soluble pheomelanins. The two most abundant trichochromes isolated from red chicken feathers are B and C, that contain a carboxyl group in the 3-position of the first benzothiazine and a keto group in the 3-position of the other unit. The isomer $\mathrm{B}$ is formed by the conjugation of 5-cysdopa with 2-cysdopa, whereas trichochrome $\mathrm{C}$ is formed by conjugation of two units of 5-cysdopa. When trichochromes $B$ and $C$ are heated in acid media, a decarboxylation takes place to yield decarboxytrichochromes, which leads to a change in color from yellow to pinky red [41]. Similar natural trichochromes E and F, devoid of carboxyl and keto groups, were be also isolated by these authors from red feathers (Rhode Island hen), although in lower amounts than trichochromes B and C (Figure 2). All these trichochromes were isolated by thin layer chromatography [41], from feathers, red hair and melanoma extracts, although red feathers showed greater number of isomers.

Concerning erythromelanins, they were hypothesized to justify the wide range of reddish color found in some bird species, but in fact, they have never been chemically characterized. Currently their existence with a different structure is doubtful Melanin granules composed by pheomelanin or mixtures of pheo- and eumelanin with other non-melanin pigments or morphological structures are enough to explain all structural colors. For a detailed anatomical description of the types of iridescent and non-irisdescent arrays of keratin, melanin and air in avian feather barbules, see [68].

In addition, during melanin synthesis, some of the o-quinonic precursor units can be conjugated not only with free cysteine or GSH, but also with thiols of side chains of a number of proteins, forming melanoproteins [69]. Melanoproteins were identified for the first time in melanin from cuttlefish ink, but were also described in other sources [31]. In animals with Dct activity, the incorporation of indole to proteins could be much lower, as this enzyme forms DHICA instead of DHI and it thus 
decreases the incorporation to the protein chain [70]. As keratins are rich in cysteine, the possibility of L-dopaquinone addition at the side chains of cysteinyl residues is a reasonable possibility that deserves being explored although most of Cys residues are involved in disulfide bridges to maintain the structural stability of keratin fibers.

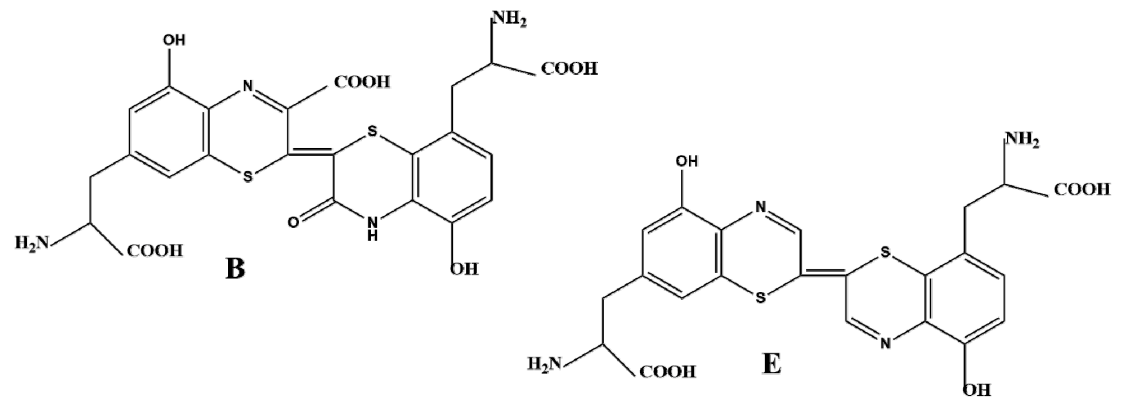

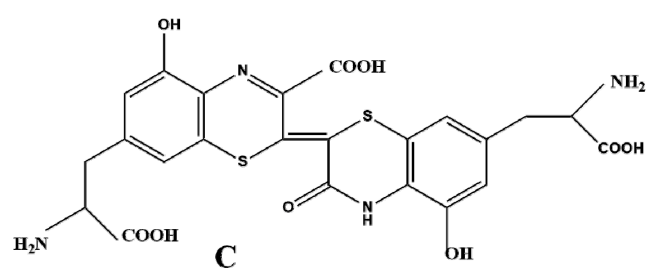<smiles>CCC(C)Cc1cc(O)c2c(c1)SC(=C1C=Cc3c(C)cc(CC(C)C)cc3S1)C=C2</smiles>

Figure 2. Trichochrome structure. These pigments are a type of phaeomelanin formed after benzothiazine dimerization. The four main structures, B, C, E and F, are shown. They have been isolated from red hair and red hen feathers.

\section{Environmental and Genetic Control on Avian Melanogenesis}

Melanin synthesis is environmentally and genetically controlled since the pathway involves precursors and traces of some metal ions mainly in the pheomelanogenesis pathway, but also enzymes and specific hormones. Melanin precursors (i.e., tyrosine, its precursor phenylalanine, and cysteine) and metal ions are acquired with the diet, thus making diet quality a potential influence on melanin pigmentation [71,72]. Furthermore, the fact that cysteine and GSH, which is the most important intracellular antioxidant, play a key role in the melanogenesis pathway makes the synthesis of melanin open to environmental factors that generate oxidative stress, as GSH is depleted under exposure to such factors [73,74].

The genetic control of avian melanogenesis is exerted by genes coding for specific enzymes involved in melanin synthesis and other important regulatory and structural proteins also needed for the process. In animals, there are more than 120 genes involved in coat color determination [75], and more than 50 of those have been identified in birds [76]. Most of these genes code for melanogenic hormones, receptors, factors for melanoblasts migration and melanocyte differentiation, structural proteins and membrane transporters. Thus, the genetic control of melanogenesis implies hormones, termed melanocortins, all derived from processing a common precursor encoded by the pro-opiomelanocortin gene. The melanocortin system consisted of $\alpha-\beta, \beta$ - and $\gamma$-melanocyte-stimulating hormones (MSH) and adrenocorticotropin (ACTH). Other important genes encode for five melanocortin receptors (MCRs) and some important regulators of the hormone-receptor interactions, as the agouti (ASIP) and agouti-related (AGRP) proteins $[77,78]$. 
Regarding receptors, melanocortin receptor $1(\mathrm{MC} 1 \mathrm{R})$ is the most important one in all animals. MC1R up-regulates the expression of tyrosinase and two enzymes specific of the eumelanogenesis pathway: Tyrp1 and Tyrp2 (Dct). The activity of this receptor switches-on/off the synthesis of black/brown eumelanin or reddish/yellowish pheomelanin, as first described in chicken [79]. When this receptor is active and functional, dark eumelanins are formed in response to melanocortins, but a number of amino acid substitutions lead to variations in plumage coloration [78]. The best characterized replacement in the avian MC1R gene is at position 92. Glu92Lys substitution locks MC1R in an active state even in the absence of the hormone, at least in the chicken and tropical birds such as the bananaquit (Coereba flaveola) [80]. On the other hand, other amino acid replacements favor pheomelanogenesis, such as Val85Met in domestic rock pigeons (Columbia livia) [81] or the conservative substitution Val126lle in barn owls (Tyto alba) [82]. Several missense mutations in this gene have been associated to almost complete white plumage color morphs rather than to eumelanin-based coloration in gyrfalcons (Falco rusticolus) [83], although the involvement of other loci different of MC1R cannot be ruled out. The association between MC1R polymorphisms and plumage coloration has been studied in 13 Spanish chicken breeds carrying six different alleles in the MC1R locus [84]. These chickens derived from domestication of a single ancestor, the red jungle fowl (Gallus gallus) and they show a variety of plumage colors. The following substitutions have been reported: Met71Thr, Glu92Lys, Val126Ile, Leu133GlnPro, Ala137Thr, Thr143Ala, Cys213Arg, His215Pro, and Val216Ile. Overall, it seems that Lys92 leads to a constitutive activated receptor leading to eumelanin production even in the absence of melanocortins, although it seems to be necessary but not sufficient to express the extended black phenotype, as the Cys213Arg change may be the cause of the loss of function to produce eumelanin, and the Ala137Thr one may be a candidate to attenuate Glu92Lys effects. Figure 3 displays the alignment of sequences of three typical avian receptors (chicken, owl and duck) in comparison with the MC1R mouse protein as a mammalian reference. A scheme of the MC1R inserted in the melanocyte membrane is also shown.
10
20
30
40
50
60

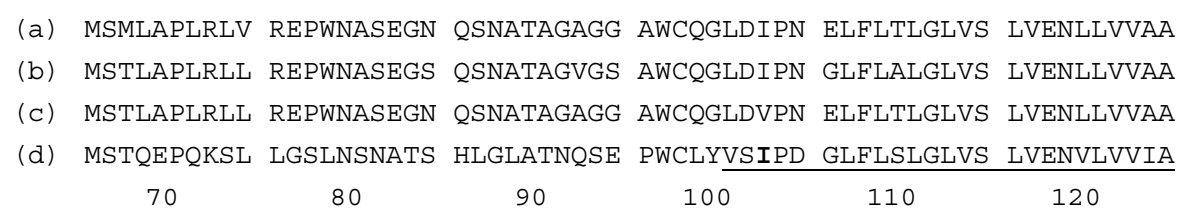
ILKNRNLHSP TYYFICCLAV SDMLVSVSNL AKTLFMLLME HGVLVIRASI VRHMDNVIDM VSKNRNLHSP TYYFICCLAV SDTLVSVSNL AETLFLLLLE HGVLVARASV VRRMDNVIDL ILKNRNLHSP MYYFICCLAV SDMLVSVSNL AETLFMLLME HGVLVIHASI IRHMDNIIDM ITKNRNLHSP MYYFICCLAL SDLMVSVSIV LETTIILLLE AGILVARVAL VQQLDNLIDV

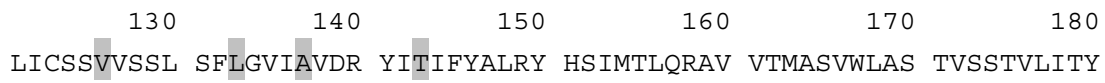 LICSSVVSSL SFLGVIAVDR YITIFYALRY HSIMTLQRAV VTMASVWLAS TVSSTVFITY LICSSVVSSL SFLGVIAVDR YITIFYALRY HSIMTLQRAV VTMASVWLAS TVSSTVFITY \begin{tabular}{rrrrrr} 
LICGSMVSSL & CFLGIIAIDR & YISIFYALRY & HSIVTLPRAR & RAVVGIWMVS & IVSSTLFITY \\
\hline 190 & 200 & 210 & 220 & 230 & 240
\end{tabular} YRNNAILLCL IGFFLFMLVL MLVLYIHMFA LACHHVRSIS SQQKQPTIYR TSS_LKGAVT YRNNAILLCL IGFFLFMLVL MLVLYIHMFA LARHHLRSIS SQQKQPTVYR SSS_LKGAVT YRNNAILLCL IGFFLFMLIL MLVLYIHMFA LARHHLCSIS SQQKHPAVYR TSS_LKGAVT YKHTAVLLCL VTFFLAMLAL MAILYAHMFT RACQHAQGIA QLHKRRRSIR QGFCLKGAAT

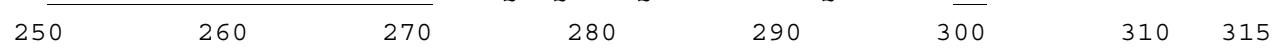
LTILLGVFFI CWGPFFFHLI LIVTCPTNPF CTCFFSYFNL FLILIICNSV VDPLIYAFRS QELRRTLREV VLCSW
LTILLGVFFI CWGPFFFHLI LIVTCPTNPF CTCFFSYFNL FHILIICNSV IDPLIYAFRS QELRRTLREV VLCSW
LTILLGVFFI CWGPFFFHLI LIVTCPTNPF CTCFFGYFNL FLILIICNSV VDPLIYAFRS QELRRTLREV VLCSW LTILLGIFFL CWGPFFLHLL LIVLCPQHPT CSCIFKNFNL FLLLIVLSST VDPLIYAFRS QELRMTLKEV LLCSW

Figure 3. Cont. 


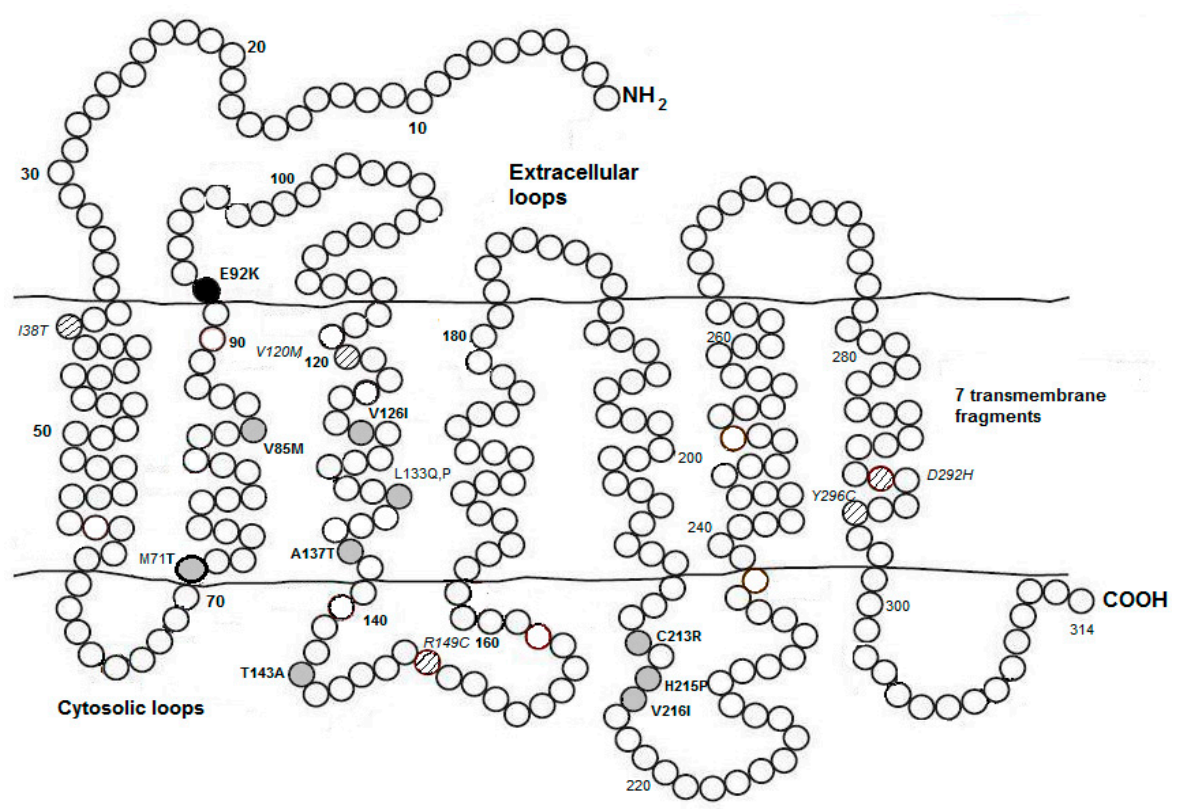

Figure 3. Melanocortin receptor 1 (MC1R) sequences and topological scheme of selected species: (a) Chicken (Red Jungle fowl, Gallus gallus) Acc. No. P55167-1; (b) Barn owl (Tyto alba), A0A0E3Z8U6-1; (c) Duck (Anas platyrhynchos) U3HZ58-1; and (d) Mouse (Mus musculus), Q01727-1. Sequences from www.expasy.org database. Transmembrane regions are underlined in the mouse sequence (line 4). Gray background residues (line 1 in sequences alignment and gray circles in scheme) are positions described in avian species determining the type and amount of melanin formed (see text for details). E92K replacement (black circle) causes constitutively-activated MC1R, so that dark melanin is formed even in the absence of hormone signal, MSH. Bold residues (line 4, in alignment, hatched circles in scheme) are mouse positions equivalent to those related to the RHC phenotype (red hair color) in the ortholog human protein. Surprisingly, most of these residues have not yet been reported as important in determining bird color plumage.

MC1R also up-regulates the main structural intramelanosomal protein, Pmel. This protein was described in birds and mammals, and its truncation gives place to the silver mutation in mice [85] has been confused for years since the protein was named differently Pmel17, gp100, gp95, gp85, ME20, RPE1, SILV, MMP115 in chicken [86], and finally simply Pmel, pre-melanosomal protein [87]. Mutations in the Pmel gene cause hypopigmentation in chicken, being responsible for the dominant white, dun and smoky alleles that inhibit the expression of black eumelanin [88] Feather-pecking in chickens, a behavior that can lead to the death of victim birds, is more frequently observed when the plumage color of the victim is associated to the expression of a wild recessive allele at the Pmel gene [89]. Thus, Pmel is important to improve welfare conditions in poultry. Concerning the enzymatic regulation of melanogenesis, tyrosinase is the most important enzyme, as it catalyzes the rate-limiting steps in the pathway. Chicken tyrosinase seems to be more acidic than the corresponding mammalian enzyme [90]. In that way, chicken and probably other avian tyrosinases seem to be adapted to act in mild acidic conditions in comparison to mammalian tyrosinase. These acidic conditions might favor pheomelanin conditions in comparison to eumelanin formation, taking into account the acidic conditions existing within melanosomes [44] and that cysteine addition is favored to L-dopaquinone cyclization under those conditions. Trp1 and Trp2 were cloned in birds [91,92], but their level of activity in follicular avian feather have been rarely determined. However, their expression has been correlated with darker pigmentation in a number of bird species, especially Trp1, which is involved in the final phase of eumelanogenesis by exerting DHICA oxidase activity [50]. Thus, both tyrosinase and Tyrp1 activity levels account for melanin-based plumage color variation in chickens, ducks, Korean quails, pigeons and geese [93-96]. The role of avian Trp2 has not been studied in depth because the Dct activity 
is not essential for eumelanogenesis, but recently some SNPs in the corresponding Trp2 gene have been associated with plumage color variation in Korean native ducks [97]. In addition to the role of $\mathrm{pH}$, other essential requirement for pheomelanin synthesis is the availability of cysteine or GSH. Certainly, protein transporters for $\mathrm{H}^{+}$, tyrosine and cysteine/GSH are needed for melanogenesis. Concerning protons, the $p$ protein (also named pink-eyed dilution protein) seems to act as a proton-dependent membrane transporter for tyrosine. Mutations in this protein are related to oculocutaneous albinism type 2 (OCA2). However, this protein has been poorly studied in the avian melanosome.

The Slc7a11 gene encodes a membrane cystine/glutamate exchanger whose inactivation reduces pheomelanin production in sut mice [75], suggesting a role in pheomelanin formation by regulating the transport of cysteine inside melanocytes. This protein is also critical for the normal proliferation of melanocytes, GSH production and cell protection against oxidative stress. In turn, a similar cystine $/ \mathrm{H}^{+}$ symporter named cystinosin has been described in lysosomes and melanosomes [98]. Mutations in cystinosin produce a decrease in eumelanin and increase in pheomelanin formation in mammalian hair. Both transporters are therefore involved in the synthesis of pheomelanin but this role has not been investigated in birds.

There are other solute carriers involved in melanization, such as the potassium-dependent sodium-calcium ion exchanger Slc24a5, whose dysfunction is responsible for human OCA6. Down-regulation of this cation exchanger reduces pigmentation in chicken [99]. On the other hand, Slc45a2, also known as MATP (membrane-associated transporter protein) in mammals, has an important role in vesicle sorting in melanocytes and in trafficking melanogenic enzymes. Its mutation causes OCA4 in humans [100] and melanin-based plumage color variation in chicken and Japanese quail. The mechanism of melanin regulation and the pattern of Scl45a2 mutations in birds is complex and poorly understood, as some mutations cause complete absence of pigmentation while other cause a specific inhibition of pheomelanogenesis [101].

Lastly, hormones that do not participate in the melanogenesis system, especially sexual steroids, also influence melanin pigmentation. This is prominently known for androgens such as testosterone, which favor the expression of dark eumelanin-based plumage traits in birds [102,103]. The influence of testosterone on eumelanogenesis could be mediated by oxidative stress generated by this hormone, which in turn may deplete GSH levels, thus promoting eumelanin synthesis [104]. It must be noted here that female birds can differentially transfer testosterone to the egg yolk [105], which leads to another source of environmental influences on melanin synthesis. Trace metals, which affect melanin synthesis as mentioned above, can also be transferred to the egg yolk [106] This capacity of females to differentially transfer testosterone and trace metals to the egg yolk also implies that cross-fostering experiments, sometimes used to estimate the heritability of melanin-based traits in birds [107], do not completely remove potential confounding parental effects and thus probably tend to overestimate heritability. In sum, melanogenesis in birds is under a relatively complex genetic control, but it is also open to at least four lines of environmental influences (trace metals, melanin precursors, environmental oxidative stress and maternally transferred testosterone and trace metals) that should be considered to understand the expression of melanin-based traits.

\section{Function and Evolution of Bird Melanins}

\subsection{Protection against $U V$ Radiation}

The ubiquitous nature of dark melanins (i.e., eumelanin) in living organisms, where they can be found from bacteria to humans, is probably related to their capacity to protect cells from the damaging effects of UV radiation. It can be stated that this represents the primary function that provides organisms with the main adaptive benefits making melanins evolve. This property is conferred by a high refractive index and broad absorption spanning across the UV-visible range of the electromagnetic spectrum, thus avoiding that cells suffer from the pro-oxidant substances generated by the highly energetic UV radiation. As a consequence, the presence of melanins in the integument is essential for 
the development of life on earth, melanization being considered the main physiological response of animals and microorganisms against the damaging effects of UV [108]. While this generalization for the protective function of melanins is strongly founded, empirical evidence for it rarely comes from organisms other than mammals, prominently humans.

Birds constitute an outstanding example of lack of evidence for the protective role of melanins against UV radiation, although it is a common assumption. Variation in melanization levels in birds has been mainly studied regarding plumage, but skin melanization, which might be most relevant for protection of the organism against UV radiation, remains unexplored in birds [109]. In this regard, it is worth mentioning the absence of knowledge about prevalence of melanoma in wild birds beyond descriptions of particular cases [110]. The diurnal and aerial habits of most birds probably make them the vertebrates most exposed to UV radiation, and investigating how frequent is melanoma in wild birds may provide interesting information on possible mechanisms to avoid the damaging effects of UV radiation.

\subsection{Protection against Mechanical Damage}

Melanins are polymers that increase the hardness of the biological tissues where they are embedded [111]. In contrast to the previous protective function against UV radiation, the capacity of melanins to increase the resistance of integumentary structures to mechanical damage has been particularly well illustrated in birds. Thus, it has experimentally been shown that feather and bill melanization makes increase the hardness of these structures [112], as well as their resistance against abrasion caused by airborne particles [113]. It is unclear, however, if different chemical forms of melanins differ in their mechanical protective capacity, although the poor integrity of melanin granules from human hair [19] leads to expect that pheomelanin-based feathers are more fragile than eumelanin-based ones. However, the only study so far investigating this issue in birds concluded that eumelanin and pheomelanin do not differ in their capacity to increase plumage strength, although chemical analyses of melanins were not conducted and composition was inferred from the color of feathers [114].

Melanins can also protect feathers from the damaging effects of feather-degrading bacteria [115]. In fact, skin melanization has been proposed to be a primitive component of innate immune defense system [116] but it has also been suggested that melanins may serve as a substrate for some species of bacteria [117]. The latter work has not been replicated in detail [118], but it would be interesting to consider it before accepting as a fact that melanins protect against any feather-degrading bacteria. Similarly, there is no firm evidence that melanized feathers protect from feather-degrading lice, as while some authors concluded that the degree of damage by these organisms to feathers is not related to melanization levels [119], the method for lice quantification has recently been criticized [120]. Again, differential protective roles of different chemical forms of melanins have not been evaluated for feather-degrading lice.

\subsection{Thermoregulation}

The wide absorbance spectrum of melanins in the UV-visible range makes that these pigments protect cells from the damaging effects of energetic UV radiation, but this also implies that melanized biological structures usually increase their temperature more easily than non-melanized, lighter structures. For animals, this represents an advantage when increasing body temperature is necessary, but is also a physiological cost when thermal limits are exceeded, especially in ectotherms [121]. Birds, like mammals, maintain a relatively constant physiological temperature, which makes that the thermal function of melanins has been less investigated in these organisms. Indeed, the role of plumage melanization in covering the thermoregulatory needs of birds is unclear (reviewed in [109]). However, maintaining a constant body temperature may represent a significant physiological cost for birds when exposed to low ambient temperatures [122], and in such circumstances the ability of black, melanized plumage patches to rapidly absorb radiant energy may be adaptive. This may 
in fact favor the evolution of melanin-based traits characteristic of bird subspecies inhabiting cool environments [123]. However, this capacity of dark melanin-based colors to absorb radiant energy may actually represent a physiological cost under high ambient temperatures, which may have led to the evolution of compensatory mechanisms such as vascularized parts of bare skin that dissipate heat and whose colors caused by blood flow interestingly may have secondarily evolved as intraspecific signals of dominance $[124,125]$. It will be interesting to consider this potential physiological cost in a context of global warming, which may create differences in the vulnerability of species to extinctions regarding their genetic basis of melanin synthesis. Differential thermoregulatory properties of different chemical forms of melanins have not been explicitly evaluated in birds, but [126] have recently reported larger and denser plumulaceous parts of dorsal feathers in the grey morph (which mainly produces eumelanin) than in the brown morph (which mainly produces pheomelanin) in tawny owls Strix aluco, suggesting a superior insulative capacity in the former. The chemical form of melanin being produced might not be responsible for these structural differences in the feathers of both color morphs, but the authors suggest that these differences may explain the lower survival of brown, pheomelanic tawny owls during cold winters [127]. In our opinion, however, the fact that those structural differences between color morphs only appear in dorsal feathers, but not in ventral feathers, may suggest that the low survival experienced by pheomelanic tawny owls during adverse winters is actually related to the chemical form of melanin. In particular, it may be related to the cost represented by the consumption of cysteine/GSH during pheomelanin synthesis under thermal stress, which generates oxidative stress and reduces GSH levels [128].

\subsection{Signaling}

As in mammals, the range of colors conferred by eumelanin and pheomelanin to different parts of the body has favored the evolution in birds of an extraordinary diversity of plumage colorations and patterns as visual signals involved in interspecific communication by conferring crypsis to avoid either being predated [129] or being detected by prey [109]. Such diversity of colorations has also made that many melanin-based color traits in birds allow transferring information about attributes of the signal bearers to conspecifics. The information that melanin-based color traits can transfer can be related to the physical and chemical properties of melanins and to the processes underlying the chemistry of melanogenesis. Thus, the optical properties of melanins favor that melanin-based traits secondarily evolve as visual signals.

Most biological signals evolve because they are honest, i.e., influence positively the receivers of the signals [130]. In animals, signal honesty can be achieved by either trade-off relationships between costs and benefits of signaling (i.e., handicaps) or by signal design (i.e., amplifiers and indices) [131]. Melanin-based color traits in birds often act as honest signals of quality, as signalers with larger or more intense color patches are perceived by conspecifics as bearers of a superior underlying genotypic quality and as a consequence achieve higher fitness benefits than others displaying smaller or less intense color patches $[132,133]$. There are probably examples of the two mechanisms that allow the evolution of honest signals (i.e., handicaps and signal designs) among melanin-based color traits in birds.

The handicap principle [134] establishes that only high-quality individuals can afford the costs derived from signal production. The fact that melanogenesis proceeds in two main branches, one in the absence of cysteine/GSH leading to eumelanin production and other in the presence of cysteine/GSH leading to pheomelanin production, is useful to understand these costs, which will be mediated by the environmental conditions of oxidative stress. This may actually agree with the observed temporal variation in female preference by male melanin-based plumage traits in birds [135], suggesting that melanin-based traits are excellent models to study environmental influences on sexual selection. Pheomelanin-based color traits will be particularly costly to produce under high stress levels, when cysteine/GSH is more necessary to combat oxidative stress and pheomelanin synthesis represents a consumption of this antioxidant resource [73,74]. Thus, it should be expected that 
high stress levels promote the evolution of pheomelanin-based signals, when these could only be produced by high-quality individuals. By contrast, low stress levels may promote the evolution of eumelanin-based color signals, as producing eumelanin under such circumstances may require getting rid of cysteine/GSH $[73,74]$. However, giving the existence of specific transporters of cysteine that can potentially regulate cysteine levels in and out of melanocytes, the latter possibility becomes less likely. This leads to speculate that pheomelanin-based color traits have a higher potential to evolve as honest signals of quality than eumelanin-based color traits, which may be in accordance with the apparent scarcity of bird species with plumage fully composed of colors typically conferred by pheomelanin (i.e., chestnut, ferruginous) and the abundance of species fully colored by eumelanin (e.g., blackbird Turdus merula, common raven Corvus corax).

Regarding signals that achieve their honesty by design, the dark colors conferred by melanins, especially eumelanin, make that alternations of melanized (black) and unmelanized (white) plumage patches achieve the highest possible level of achromatic contrast and therefore generate very conspicuous traits. As a consequence, these unmelanized patches easily amplify properties of the bearers, for example their social status by improving the perception by others of feather damages produced by attacks received from conspecifics [136,137], or their capacity to perform ritualized movement displays [138]. These signals are honest because their design make impossible that the bearers' attributes being transferred are faked. Thus, when melanin-based color traits evolve as signals, the size or intensity of color patches use is handicapped while patterns of melanized/unmelanized patches have a greater capacity to be amplifiers and indices.

Melanin-based color traits in birds have not only improved our understanding of the costs that maintain the honesty of signals, but have also provided insight into the evolution of signal honesty. Thus, for the black bib of the house sparrow Passer domesticus, whose size acts as a honest signal of quality, it has been proposed that the mechanism by which cysteine is consumed to produce pheomelanin in the bib feathers may be functional in high-quality birds but uncoupled in low-quality birds. As large signals are produced with low contents of pheomelanin in feathers (in the case of the black bib of house sparrows and other species as well [139], this would prevent low-quality birds from producing signals unproportionally large for their quality independently of the prevailing environmental conditions of oxidative stress [140]. Further explorations of this possibility may transform our view of biological communication, as signal honesty may be physiologically maintained without the need of production costs. Moreover, this also implies that the genes involved in pheomelanin synthesis may actually determine the basis of the concept of genotypic quality, at least for melanin-based color signals [140].

\section{The Challenge of Pheomelanin Evolution}

A particularly interesting issue in the study of melanins is the evolution of pheomelanin. This melanin form requires a consumption of cysteine/GSH and, as opposite to eumelanin, produces pro-oxidant species under exposure to UV radiation and probably also under exposure to ionizing radiation [141]. Therefore, why has this pigment evolved? This unsolved issue has led some authors to consider pheomelanin an accident of nature [142]. Adaptive benefits might be the response to this question, and studies with birds have been pioneering in exploring the adaptive benefits that pheomelanin may provide. Indeed, the consumption of cysteine during pheomelanogenesis may be adaptive in certain circumstances in which this amino acid is in excess and potentially toxic [143]. Studies on several species of birds have shown that producing pheomelanin can be beneficial and increase survival if there is no evidence of particularly high levels of environmental oxidative stress [144], but is also involved in physiological trade-offs as shown by negative relationships between the extent of plumage colored by pheomelanin and brain size [145], capacity to resist the effects of ionizing radiation [141], physiological stress caused by corticosterone [146], and survival during adverse environmental conditions [127]. The evolution of pheomelanin may therefore respond to the benefits conferred by the synthesis of this pigment by avoiding excess cysteine under low levels 
of environmental stress, representing a physiological cost under high levels of environmental stress. A promising avenue for future research will be to identify particular environmental conditions that the production of pheomelanin helps to cope with, in birds and other animals including humans.

Acknowledgments: Ismael Galván was supported by a Ramón y Cajal Fellowship (ref. RYC-2012-10237) from the Spanish Ministry of Economy and Competitiveness. Francisco Solano belongs to the research group supported with the grant 19875/GERM/15 from Seneca Foundation, CARM, Spain.

Author Contributions: Ismael Galván and Francisco Solano equally contributed to design and discuss the whole manuscript.

Conflicts of Interest: The authors declare no conflict of interest.

\section{References}

1. Darwin, C. The Descent of Man, and Selection in Relation to Sex; Murray: London, UK, 1871.

2. Cott, H.B. Adaptive Coloration in Animals; Methuen, Oxford University Press: London, UK, 1940.

3. Hoekstra, H.E.; Hirschmann, R.J.; Bundey, R.A.; Insel, P.A.; Crossland, J.P. A single amino acid mutation contributes to adaptive beach mouse color pattern. Science 2006, 313, 101-104. [CrossRef] [PubMed]

4. D'Alba, L.; Kieffer, L.; Shawkey, M.D. Relative contributions of pigments and biophotonic nanostructures to natural color production: A case study in budgerigar (Melopsittacus. undulatus) feathers. J. Exp. Biol. 2012, 215, 1272-1277. [CrossRef] [PubMed]

5. Negro, J.J.; Blasco, R.; Rosell, J.; Finlayson, C. Potential exploitation of avian resources by fossil hominins: An overview from ethnographic and historical data. Quat. Int. 2016. [CrossRef]

6. McGraw, K.J. Mechanics of uncommon colors: Pterins, porphyrins, and psittacofulvins. In Bird Coloration; Hill, G.H., McGraw, K.J., Eds.; Harvard University Press: Harvard, MS, USA, 2006; Volume 1, pp. 354-398.

7. Delhey, K. The colour of an avifauna: A quantitative analysis of the colour of Australian birds. Sci. Rep. 2015, 5, 1-12. [CrossRef] [PubMed]

8. McGraw, K.J.; Safra, R.J.; Evans, M.R.; Wakamatsu, K. European barn swallows use melanin pigments to color their feathers brown. Behav. Ecol. 2004, 15, 889-891.

9. Solano, F. Melanins: Skin Pigments and Much More. Types, Structural Models, Biological Functions and Formation Routes. New J. Sci. 2014, 1, 1-28.

10. Carr, J.G. Internal structure of avian melanin granules: An electron microscope study. J. Cell. Sci. 1957, 98, 159-162.

11. Brumbaugh, J.A. Ultrastructure differences between forming eumelanin and pheomelanin as revealed by the pink-eye mutation in the fowl. Dev. Biol. 1968, 18, 375-390. [CrossRef]

12. Brumbaugh, J.A.; Lee, K.W. Types of genetic mechanisms controlling melanogenesis in the fowl. Pigment Cell 1976, 3, 165-176.

13. Maul, G.G.; Brumbaugh, J.A. On the possible function of coated vesicles in melanogenesis of the regenerating fowl feather. J. Cell Biol. 1971, 48, 41-48. [CrossRef] [PubMed]

14. Jimbow, K.; Takeuchi, T. Ultrastructural comparison of pheo- and eumelanogenesis in animals. Pigment Cell 1979, 4, 308-317.

15. Tarafder, A.K.; Bolasco, G.; Correia, M.S.; Pereira, F.J.; Iannone, L.; Hume, A.N.; Kirkpatrick, N.; Picardo, M.; Torrisi, M.R.; Rodrigues, I.P.; et al. Rab11b mediates melanin transfer between donor melanocytes and acceptor keratinocytes via coupled exo/endocytosis. J. Investig. Dermatol. 2014, 134, 1056-1066. [PubMed]

16. Lin, S.J.; Foley, J.; Jiang, T.X.; Yeh, C.Y.; Wu, P.; Foley, A.; Yen, C.M.; Huang, Y.C.; Cheng, H.C.; Chen, C.F.; et al. Topology of feather melanocyte progenitor niche allows complex pigment patterns to emerge. Science 2013, 340, 1442-1445.

17. Zhang, F.; Kearns, S.L.; Orr, P.J.; Benton, M.J.; Zhou, Z.; Johnson, D.; Xu, X.; Wang, X. Fossilized melanosomes and the colour of Cretaceous dinosaurs and birds. Nature 2010, 463, 1075-1078. [CrossRef] [PubMed]

18. Wogelius, R.A.; Manning, P.L.; Barden, H.E.; Edwards, N.P.; Webb, S.M.; Sellers, W.I.; Taylor, K.G.; Larson, P.L.; Dodson, P.; You, H.; et al. Trace metals as biomarkers for eumelanin pigment in the fossil record. Science 2011, 333, 1622-1626. [PubMed] 
19. Liu, Y.; Hong, L.; Wakamatsu, K.; Ito, S.; Adhyaru, B.; Cheng, C.Y.; Bowers, C.R.; Simon, J.D. Comparison of structural and chemical properties of black and red human hair melanosomes. Photochem. Photobiol. 2005, 81, 135-144. [CrossRef] [PubMed]

20. Colleary, C.; Dolocan, A.; Gardner, J.; Singh, S.; Wuttke, M.; Rabenstein, R.; Habersetzer, J.; Schaal, S.; Feseha, M.; Clemens, M.; et al. Chemical, experimental, and morphological evidence for diagenetically altered melanin in exceptionally preserved fossils. Proc. Natl. Acad. Sci. USA 2015, 112, 12592-12597. [PubMed]

21. Clarke, J.A.; Ksepka, D.T.; Salas-Gismondi, R.; Altamirano, A.J.; Shawkey, M.D.; d'Alba, L.; Vinther, J.; DeVries, T.J.; Baby, P. Fossil evidence for evolution of the shape and color of penguin feathers. Science 2010, 330, 954-957. [CrossRef] [PubMed]

22. Li, Q.; Gao, K.Q.; Vinther, J.; Shawkey, M.D.; Clarke, J.A.; d'alba, L.; Meng, Q.; Briggs, D.E.; Prum, R.O. Plumage color patterns of an extinct dinosaur. Science 2010, 327, 1369-1372. [CrossRef] [PubMed]

23. Li, Q.; Clarke, J.A.; Gao, K.Q.; Zhou, C.F.; Meng, Q.; Li, D.; D'Alba, L.; Shawkey, M.D. Melanosome evolution indicates a key physiological shift within feathered dinosaurs. Nature 2014, 507, 350-353. [CrossRef] [PubMed]

24. Carney, R.M.; Vinther, J.; Shawkey, M.D.; D'Alba, L.; Ackermann, J. New evidence on the colour and nature of the isolated Archaeopteryx feather. Nat. Commun. 2012, 3, 637. [CrossRef] [PubMed]

25. Vinther, J. Fossil melanosomes or bacteria? A wealth of findings favours melanosomes. BioEssays 2016, 38, 220-225. [PubMed]

26. McGraw, K.J.; Wakamatsu, K.; Ito, S.; Nolan, P.M.; Jouventin, P.; Dobson, F.S.; Austic, R.E.; Safran, R.J.; Siefferman, L.M.; Hill, G.E.; et al. You can't judge a pigment by its color: Carotenoids and melanin content of yellow and brown feathers in swallows, bluebirds, penguins, and domestic chickens. Condor 2004, 106, 390-395.

27. Ito, S.; Fujita, K. Microanalysis of eumelanin and pheomelanin in hair and melanomas by chemical degradation and liquid chromatography. Anal. Biochem. 1985, 144, 527-536. [CrossRef]

28. Ito, S.; Wakamatsu, K. Quantitative analysis of eumelanin and pheomelanin in humans, mice, and other animals: A comparative review. Pigment Cell Res. 2003, 16, 523-531. [CrossRef] [PubMed]

29. Ito, S.; Wakamatsu, K.; d'Ischia, M.; Napolitano, A.; Pezzella, A. Structure of melanins. In Melanins and Melanosomes: Biosynthesis, Structure, Physiological and Pathological Functions; Borovansky, J., Riley, P.A., Eds.; Willey-Blackwell: Weinheim, Germany, 2011; pp. 167-185.

30. Ito, S.; Wakamatsu, K.; Glass, K.; Simon, J.D. High-performance liquid chromatography estimation of cross-linking of dihydroxyindole moiety in eumelanin. Anal. Biochem. 2013, 434, 221-225. [CrossRef] [PubMed]

31. D'Ischia, M.; Wakamatsu, K.; Napolitano, A.; Briganti, S.; Garcia-Borron, J.C.; Kovacs, D.; Meredith, P.; Pezzella, A.; Picardo, M.; Sarna, T.; et al. Melanins and melanogenesis: Methods, standards, protocols. Pigment Cell Melanoma Res. 2013, 26, 616-633. [PubMed]

32. Liu, S.Y.; Shawkey, M.D.; Parkinson, D.; Tyler, P.; Troy, T.P.; Ahmed, M. Elucidation of the chemical composition of avian melanin. RSC Adv. 2014, 4, 40396-40399. [CrossRef]

33. Dernroth, D.N.; Rundström, A.A.; Kågedal, B. Gas chromatography-mass spectrometry analysis of pheomelanin degradation products. J. Chromatog. A 2009, 1216, 5730-5739. [CrossRef] [PubMed]

34. Chen, S.R.; Jiang, B.; Zheng, J.X.; Xu, G.Y.; Li, J.Y.; Yang, N. Isolation and characterization of natural melanin derived from silky fowl (Gallus gallus domesticus Brisson). Food Chem. 2008, 111, 745-749. [CrossRef]

35. Galván, I.; Solano, F. Melanin chemistry and the ecology of stress. Physiol. Biochem. Zool. 2015, 88, 352-355. [CrossRef] [PubMed]

36. Galván, I.; Jorge, A. Dispersive Raman spectroscopy allows the identification and quantification of melanin types. Ecol. Evol. 2015, 5, 1425-1431. [CrossRef] [PubMed]

37. Raper, H.S. The aerobic oxidases. Physiol. Rev. 1928, 8, 245-282.

38. Mason, H.S. The chemistry of melanin III. Mechanism of the oxidation of dihydroxyphenylalanine by tyrosinase. J. Biol. Chem. 1948, 172, 83-99. [PubMed]

39. Prota, G.; Nicolaus, R.A. On the biogenesis of phaeomelanins. In The Pigmentary System; Montagna, W., Flu, F., Eds.; Pergamon Press: New York, NY, USA, 1967; Volume 8, pp. 323-328.

40. Agrup, G.; Falck, B.; Kennedy, B.M.; Rorsman, H.; Rosengren, A.M.; Rosengren, E. Formation of cysteinyldopa from glutathionyldopa in melanoma. Acta Dermatol. Venereol. (Stockholm) 1975, 55, 1-3. 
41. Rorsman, H.; Agrup, G.; Hansson, C.; Rosengren, A.M.; Rosengren, E. Detection of Phaeomelanins. Pigment Cell 1979, 4, 244-252.

42. Olivares, C.; Solano, F. New insights into the active site structure and catalytic mechanism of tyrosinase and its related proteins. Pigment Cell Melanoma Res. 2009, 22, 750-760. [CrossRef] [PubMed]

43. Ito, S.; Wakamatsu, K. Chemistry of mixed melanogenesis-Pivotal roles of dopaquinone. Photochem. Photobiol. 2008, 84, 582-592. [CrossRef] [PubMed]

44. Ancans, J.; Tobin, D.J.; Hoogduijn, M.J.; Smit, N.P.; Wakamatsu, K.; Thody, A.J. Melanosomal pH controls rate of melanogenesis, eumelanin/phaeomelanin ratio and melanosome maturation in melanocytes and melanoma cells. Exp. Cell Res. 2001, 268, 26-35. [CrossRef] [PubMed]

45. Aroca, P.; García-Borrón, J.C.; Solano, F.; Lozano, J.A. Regulation of distal mammalian melanogenesis. I: Partial purification and characterization of a dopachrome converting factor: Dopachrome tautomerase. Biochim. Biophys. Acta 1990, 1035, 266-275. [PubMed]

46. Aroca, P.; Solano, F.; García-Borrón, J.C.; Salinas, C.; Lozano, J.A. Regulation of the final phase of mammalian melanogenesis. Eur. J. Biochem. 1992, 208, 155-163. [CrossRef] [PubMed]

47. Solano, F.; Martínez-Liarte, J.H.; Jiménez-Cervantes, C.; García-Borrón, J.C.; Lozano, J.A. Dopachrome tautomerase is a zinc-containing enzyme. Biochem. Biophys. Res. Commun. 1994, 204, 1243-1250. [CrossRef] [PubMed]

48. Palumbo, A.; Solano, F.; Misuraca, G.; Aroca, P.; Garcia-Borron, J.C.; Lozano, J.A.; Prota, G. Comparative action of dopachrome tautomerase and metal ions on the rearrangement of dopachrome. Biochim. Biophys. Acta 1991, 1115, 1-5. [CrossRef]

49. Nadeau, N.J.; Burke, T.; Mundy, N.I. Evolution of an avian pigmentation gene correlates with a measure of sexual selection. Proc. R. Soc. B 2007, 274, 1807-1813. [CrossRef] [PubMed]

50. Jiménez-Cervantes, C.; Solano, F.; Kobayashi, T.; Urabe, K.; Hearing, V.; Lozano, J.A.; García-Borrón, J.C. A new enzymatic function in the melanogenic pathway. The 5,6-dihydroxyindole-2-carboxylic acid oxidase activity of tyrosinase related protein-1. J. Biol. Chem. 1994, 269, 17993-18001. [PubMed]

51. Olivares, C.; Jimenez-Cervantes, C.; Lozano, J.A.; Solano, F.; Garcia-Borron, J.C. The 5,6-dihydroxyindole2-carboxylic acid (DHICA) oxidase activity of human tyrosinase. Biochem. J. 2001, 354, 131-139. [CrossRef] [PubMed]

52. Jara, J.R.; Aroca, P.; Solano, F.; Martínez, J.H.; Lozano, J.A. The role of sulfhydryl compounds in mammalian melanogenesis: The effect of cysteine and glutathione upon tyrosinase and the intermediates of the pathway. Biochim. Biophys. Acta 1988, 967, 296-303. [CrossRef]

53. Wakamatsu, K.; Ohtara, K.; Ito, S. Chemical analysis of late stages of pheomelanogenesis, conversion of dihydrobenzothiazine to a benzothiazole structure. Pigment Cell Melanoma Res. 2009, 22, 474-486. [CrossRef] [PubMed]

54. Ito, S.; Nakanishi, Y.; Valenzuela, R.K.; Brilliant, M.H.; Kolbe, L.; Wakamatsu, K. Usefulness of alkaline hydrogen peroxide oxidation to analyze eumelanin and pheomelanin in various tissue samples: Application to chemical analysis of human hair melanins. Pigment Cell Melanoma Res. 2011, 24, 605-613. [CrossRef] [PubMed]

55. Sato, C.; Ito, S.; Takeuchi, T. Enhancement of pheomelanogenesis by L-dopa in the mouse melanocyte cell line, TM10, in vitro. J. Cell Sci. 1987, 87, 507-512. [PubMed]

56. Napolitano, A.; Costantini, C.; Crescenzi, O.; Prota, G. Characterisation of 1,4-benzothiazine intermediates in the oxidative conversion of 5-S-cysteinyldopa to pheomelanins. Tetrahedron Lett. 1994, 35, 6365-6368. [CrossRef]

57. Napolitano, A.; di Donato, P.; Prota, G.; Land, E.J. Transient quinonimines and 1,4-benzothiazines of pheomelanogenesis: New pulse radiolytic and spectrophotometric evidence. Free Radic. Biol. Med. 1999, 27, 521-528. [CrossRef]

58. Napolitano, A.; di Donato, P.; Prota, G. New regulatory mechanisms in the biosynthesis of pheomelanins: Rearrangement $v s$. redox exchange reaction routes of a transient $2 H$-1,4-benzothiazine-o-quinonimine intermediate. Biochim. Biophys. Acta 2000, 1475, 47-54. [PubMed]

59. Napolitano, A.; Vicensi, M.R.; d'Ischia, M.; Prota, G. A new benzothiazole derivative by degradation of pheomelanins with alkaline hydrogen peroxide. Tetrahedron Lett. 1996, 37, 6799-6802. [CrossRef]

60. Tesema, Y.T.; Pham, D.M.; Franz, K.J. Counterions Influence Reactivity of Metal Ions with Cysteinyldopa Model Compounds. Inorg. Chem. 2008, 47, 1087-1095. [CrossRef] [PubMed] 
61. Greco, G.; Panzella, L.; Verotta, L.; d'Ischia, M.; Napolitano, A. Uncovering the structure of human red hair pheomelanin: Benzothiazolylthiazinodihydroisoquinolines as key building blocks. J. Nat. Prod. 2011, 74, 675-682. [CrossRef] [PubMed]

62. Di Donato, P.; Napolitano, A.; Prota, G. Metal ions as potential regulatory factors in the biosynthesis of red hair pigments: A new benzothiazole intermediate in the iron or copper assisted oxidation of 5-S-cysteinyldopa. Biochim. Biophys. Acta 2002, 1571, 157-166. [CrossRef]

63. Napolitano, A.; Panzella, L.; Leone, L.; d'Ischia, M. Red hair benzothiazines and benzothiazoles: Mutation-inspired chemistry in the quest for functionality. Acc. Chem. Res. 2013, 46, 519-528. [CrossRef] [PubMed]

64. Napolitano, A.; di Donato, P.; Prota, G. Zinc-catalyzed oxidation of 5-S-Cysteinyldopa to 2,2'-Bi(2H-1,4benzothiazine): Tracking the biosynthetic pathway of trichochromes, the characteristic pigments of red hair. J. Org. Chem. 2001, 66, 6958-6966. [CrossRef] [PubMed]

65. Li, Y.; Liu, J.; Wang, Y.; Chan, H.W.; Wang, L.; Chan, W. Mass spectrometric and spectrophotometric analyses reveal an alternative structure and a new formation mechanism for melanin. Anal. Chem. 2015, 87, 7958-7963. [CrossRef] [PubMed]

66. Galván, I.; Wakamatsu, K.; Alonso-Alvarez, C.; Solano, F. Buthionine sulfoximine diverts the melanogenesis pathway toward the production of more soluble and degradable pigments. Bioorg. Med. Chem. Lett. 2014, 24, 2150-2154. [CrossRef] [PubMed]

67. Hudon, J. Considerations in the conservation of feathers and hair, particularly their pigments. In Proceedings of the CAC/ACCR 31st Annual Conference, Jasper, AB, Canada, May 2005; pp. 127-147.

68. Prum, R.O. Anatomy, physics, and evolution of avian structural colors. In Bird Coloration; Hill, G.E., McGraw, K.J., Eds.; Harvard University Press: Cambridge, MA, USA, 2006; Volume 1, pp. 295-353.

69. García-Borrón, J.C.; Saura, M.D.; Solano, F.; Iborra, J.L.; Lozano, J.A. Water and protein interactions with model melanins. In Biological, Molecular and Clinical Aspects of Pigmentation; Bagnara, J., Klaus, S.N., Paul, E., Schartl, M., Eds.; University of Tokyo Press: Tokyo, Japan, 1984; pp. 91-95.

70. Salinas, C.; García-Borrón, J.C.; Solano, F.; Lozano, J.A. Dopachrome tautomerase decreases the binding of indolic melanogenesis intermediates to proteins. Biochim. Biophys. Acta 1994, 1204, 53-60. [CrossRef]

71. Poston, J.P.; Hasselquist, D.; Stewart, I.R.K.; Westneat, D.F. Dietary amino acids influence plumage traits and immune responses of male house sparrows, Passer domesticus, but not as expected. Anim. Behav. 2005, 70, 1171-1181. [CrossRef]

72. Galván, I.; Bijlsma, R.G.; Negro, J.J.; Jarén, M.; Garrido-Fernández, J. Environmental constraints for plumage melanization in the northern goshawk Accipiter gentilis. J. Avian Biol. 2010, 41, 523-531. [CrossRef]

73. Galván, I.; Alonso-Alvarez, C. The expression of melanin-based plumage is separately modulated by exogenous oxidative stress and a melanocortin. Proc. R. Soc. Lond. B: Biol. Sci. 2009, 276, 3089-3097. [CrossRef] [PubMed]

74. Galván, I.; Solano, F. The evolution of eu- and pheomelanic traits may respond to an economy of pigments related to environmental oxidative stress. Pigment Cell Melanoma Res. 2009, 22, 339-342. [CrossRef] [PubMed]

75. Chintala, S.; Li, W.; Lamoreux, M.L.; Ito, S.; Wakamatsu, K.; Sviderskaya, E.V.; Bennett, D.C.; Park, Y.M.; Gahl, W.A.; Huizing, M.; et al. Slc7a11 gene controls production of pheomelanin pigment and proliferation of cultured cells. Proc. Natl. Acad. Sci. USA 2005, 102, 10964-10969. [PubMed]

76. Van Grouw, H. What colour is that bird? The causes and recognition of common colour aberrations in birds. Brit. Birds 2013, 106, 17-29.

77. Nadeau, N.J.; Minvielle, F.; Ito, S.; Inoue-Murayama, M.; Gourichon, D.; Follett, S.A.; Burke, T.; Mundy, N.I. Characterization of Japanese quail yellow as a genomic deletion upstream of the avian homolog of the mammalian ASIP (agouti) gene. Genetics 2008, 178, 777-786. [CrossRef] [PubMed]

78. Mundy, N.I. A window on the genetics of evolution: MC1R and plumage colouration in birds. Proc. R. Soc. Lond. B: Biol. Sci. 2005, 272, 1633-1640. [CrossRef] [PubMed]

79. Takeuchi, S.; Suzuki, H.; Yabuuchi, M.; Takahashi, S. A possible involvement of melanocortin 1-receptor in regulating feather color pigmentation in the chicken. Biochim. Biophys. Acta 1996, 1308, 164-168. [CrossRef]

80. Theron, E.; Hawkins, K.; Bermingham, E.; Ricklefs, R.E.; Mundy, N.I. The molecular basis of an avian plumage polymorphism in the wild: A melanocortin-1-receptor point mutation is perfectly associated with the melanic plumage morph of the bananaquit, Coereba flaveola. Curr. Biol. 2001, 11, 550-557. [CrossRef] 
81. Guernsey, M.W.; Ritscher, L.; Miller, M.A.; Smith, D.A.; Schöneberg, T.; Shapiro, M.D. A Val85Met mutation in melanocortin-1 receptor is associated with reductions in eumelanic pigmentation and cell surface expression in domestic rock pigeons (Columba livia). PLoS ONE 2013, 8, e74475. [CrossRef] [PubMed]

82. San-José, L.M.; Ducrest, A.L.; Ducret, V.; Béziers, P.; Simon, C.; Wakamatsu, K.; Roulin, A. Effect of the MC1R gene on sexual dimorphism in melanin-based colorations. Mol. Ecol. 2015, 24, 2794-2808. [CrossRef] [PubMed]

83. Zhan, X.J.; Dixon, A.; Fox, N.C.; Bruford, M.W. Missense SNP of the MC1R gene is associated with plumage variation in the Gyrfalcon (Falco rusticolus). Anim. Genet. 2012, 43, 460-462. [CrossRef] [PubMed]

84. Dávila, S.G.; Gil, M.G.; Resino-Talaván, P.; Campo, J.L. Association between polymorphism in the melanocortin 1 receptor gene and E locus plumage color phenotype. Poult. Sci. 2014, 3, 1089-1096. [CrossRef] [PubMed]

85. Martínez-Esparza, M.; Jiménez-Cervantes, C.; Bennett, D.C.; Lozano, J.A.; Solano, F.; García-Borrón, J.C. The murine silver locus: Coding and expression of a single transcript truncated by the silver mutation. Mamm. Genome 1999, 10, 1168-1171. [CrossRef] [PubMed]

86. Mochii, M.; Agata, M.; Eguchi, G. Complete sequence and expression of a cDNA encoding a chicken 115-kda melanosomal matrix protein. Pigment Cell Res. 1991, 4, 41-47. [CrossRef] [PubMed]

87. Theos, A.C.; Truschel, S.T.; Raposo, G.; Marks, M.S. The Silver locus product Pmel17/gp100/Silv/ME20: Controversial in name and in function. Pigment Cell Melanoma Res. 2005, 18, 322-336. [CrossRef] [PubMed]

88. Kerje, S.; Sharma, P.; Gunnarsson, U.; Kim, H.; Bagchi, S.; Fredriksson, R.; Schütz, K.; Jensen, P.; von Heijne, G.; Okimoto, R.; et al. The Dominant white, Dun and Smoky color variants in chicken are associated with insertion/deletion polymorphisms in the PMEL17 gene. Genetics 2004, 168, 1507-1518. [PubMed]

89. Keeling, L.; Andersson, L.; Schütz, K.E.; Kerje, S.; Fredriksson, R.; Carlborg, O.; Cornwallis, C.K.; Pizzari, T.; Jensen, P. Chicken genomics: Feather-pecking and victim pigmentation. Nature 2004, 431, 645-646. [CrossRef] [PubMed]

90. Yamamoto, H.; Brumbaugh, J.A. Purification and isoelectric heterogeneity of chicken tyrosinase. Biochim. Biophys. Acta 1984, 800, 282-290. [CrossRef]

91. April, C.S.; Jackson, I.J.; Kidson, S.H. Molecular cloning and sequence analysis of a chicken cDNA encoding tyrosinase-related protein-2/DOPAchrome tautomerase. Gene 1998, 219, 45-53. [CrossRef]

92. April, C.S.; Jackson, I.J.; Kidson, S.H. The cloning and sequencing of a cDNA coding for chick tyrosinase-related protein-1. Biochim. Biophys. Acta 1998, 1395, 7-12. [CrossRef]

93. Liu, W.B.; Chen, S.R.; Zheng, J.X.; Qu, L.J.; Xu, G.Y.; Yang, N. Developmental phenotypic-genotypic associations of tyrosinase and melanocortin 1 receptor genes with changing profiles in chicken plumage pigmentation. Poult. Sci. 2010, 89, 1110-1114. [CrossRef] [PubMed]

94. Domyan, E.T.; Guernsey, M.W.; Kronenberg, Z.; Krishnan, S.; Boissy, R.E.; Vickrey, A.I.; Rodgers, C.; Cassidy, P.; Leachman, S.A.; Fondon, J.W.; et al. Epistatic and combinatorial effects of pigmentary gene mutations in the domestic pigeon. Curr. Biol. 2014, 24, 459-464.

95. Wang, Y.; Li, S.M.; Huang, J.; Chen, S.Y.; Liu, Y.P. Mutations of TYR and MITF genes are associated with plumage colour phenotypes in geese. Asian Austral. J. Anim. Sci. 2014, 27, 778-783. [CrossRef] [PubMed]

96. Xu, Y.; Zhang, X.H.; Pang, Y.Z. Association of tyrosinase (TYR) and tyrosinase related protein 1 (TYRP1) with melanic plumage color in Korean quails (Coturnix. coturnix). Asian Austral. J. Anim. Sci. 2013, 26, 1518-1522. [CrossRef] [PubMed]

97. Sultana, H.; Seo, D.W.; Park, H.B.; Cahyadi, M.; Jin, S.; Hoque, R.; Kim, Y.S.; Heo, K.N.; Jo, C.; Gotoh, T.; Lee, J.H. Identification of polymorphisms in plumage color related genes in Korean native ducks. J. Fac. Agric. Kyushu Univ. 2015, 60, 119-126.

98. Chiaverini, C.; Sillard, L.; Flori, E.; Ito, S.; Briganti, S.; Wakamatsu, K.; Fontas, E.; Berard, E.; Cailliez, M.; Cochat, P.; et al. Cystinosin is a melanosomal protein that regulates melanin synthesis. FASEB J. 2012, 26, 3779-3789. [PubMed]

99. Liu, X.F.; Luo, J.; Hu, X.X.; Yang, H.; Lv, X.Q.; Feng, C.G.; Tong, J.; Wang, Y.Q.; Wang, S.H.; Liu, X.J.; et al. Repression of Slc24a5 can reduce pigmentation in chicken. Front. Biosci. 2011, 3, 158-165.

100. Straniero, L.; Rimoldi, V.; Solda, G.; Mauri, L.; Manfredini, E.; AndreuccI, E.; Bargiacchi, S.; Penco, S.; Giovanni, P.; Gesu, G.P.; et al. Two novel splicing mutations in the SLC45A2 gene cause Oculocutaneous Albinism Type IV by unmasking cryptic splice sites. J. Hum. Gen. 2015, 60, 467-471. 
101. Gunnarsson, U.; Hellström, A.R.; Tixier-Boichard, M.; Minvielle, F.; Bed'Hom, B.; Ito, S.; Jensen, P.; Rattink, A.; Vereijken, A.; Andersson, L. Mutations in SLC45A2 cause plumage color variation in chicken and Japanese quail. Genetics 2007, 175, 867-877. [CrossRef] [PubMed]

102. Strasser, R.; Schwabl, H. Yolk testosterone organizes behavior and male plumage coloration in house sparrows (Passer domesticus). Behav. Ecol. Sociobiol. 2004, 56, 491-497. [CrossRef]

103. Eising, C.M.; Müller, W.; Groothuis, T.G.G. Avian mothers create different phenotypes by hormone deposition in their eggs. Biol. Lett. 2006, 2, 20-22. [CrossRef] [PubMed]

104. Galván, I.; Alonso-Alvarez, C. Yolk testosterone shapes the expression of a melanin-based signal in great tits: an antioxidant-mediated mechanism? J. Exp. Biol. 2010, 213, 3127-3130. [CrossRef] [PubMed]

105. Müller, W.; Eens, M. Elevated yolk androgen levels and the expression of multiple sexually selected male characters. Horm. Behav. 2009, 55, 175-181. [CrossRef] [PubMed]

106. Surai, P.F. Effect of selenium and vitamin E content of the maternal diet on the antioxidant system of the yolk and the developing chick. Br. Poult. Sci. 2000, 41, 235-243. [CrossRef] [PubMed]

107. Roulin, A.; Dijkstra, C. Genetic and environmental components of variation in eumelanin and phaeomelanin sex-traits in the barn owl. Heredity 2003, 90, 359-364. [CrossRef] [PubMed]

108. Brenner, M.; Hearing, V.J. The protective role of melanin against UV damage in human skin. Photochem. Photobiol. 2008, 84, 539-549. [CrossRef] [PubMed]

109. Bortolotti, G.R. Natural selection and coloration: Protection, concealment, advertisement, or deception? In Bird Coloration; Hill, G.E., McGraw, K.J., Eds.; Harvard University Press: Cambridge, MS, USA, 2006; Volumn 2, pp. 3-35.

110. Dillberger, J.E.; Citino, S.B.; Altman, N.H. Four cases of neoplasia in captive wild birds. Avian Dis. 1987, 31, 206-213. [CrossRef] [PubMed]

111. Moses, D.N.; Mattoni, M.A.; Slack, N.L.; Waite, J.H.; Zok, F.W. Role of melanin in mechanical properties of Glycera jaws. Acta Biomater. 2006, 2, 521-530. [CrossRef] [PubMed]

112. Bonser, R.H.C. Melanin and the abrasion resistance of feathers. Condor 1995, 97, 590-591.

113. Schreiber, R.W.; Schreiber, E.; Peele, A.M.; Burtt, E.H., Jr. Pattern of damage to albino Great Frigatebird flight feathers supports hypothesis of abrasion by airborne particles. Condor 2006, 108, 736-741. [CrossRef]

114. Pannkuk, E.L.; Siefferman, L.M.; Butts, J.A. Colour phases of the eastern screech owl: A comparison of biomechanical variables of body contour feathers. Funct. Ecol. 2010, 24, 347-353. [CrossRef]

115. Burtt, E.H., Jr.; Ichida, J.M. Occurrence of feather-degrading bacilli in the plumage of birds. Auk 1999, 116, 364-372. [CrossRef]

116. Mackintosh, J.A. The antimicrobial properties of melanocytes, melanosomes and melanin and the evolution of black skin. J. Theor. Biol. 2001, 211, 101-113. [CrossRef] [PubMed]

117. Grande, J.M.; Negro, J.J.; Torres, M.J. The evolution of bird plumage colouration: A role for feather-degrading bacteria? Ardeola 2004, 51, 375-383.

118. Gunderson, A.R.; Frame, A.M.; Swaddle, J.P.; Forsyth, M.H. Resistance of melanized feathers to bacterial degradation: Is it really so black and white? J. Avian Biol. 2008, 39, 539-545. [CrossRef]

119. Bush, S.E.; Kim, D.; Moyer, B.R.; Lever, J.; Clayton, D.H. Is melanin a defense against feather-feeding lice? Auk 2006, 123, 153-161. [CrossRef]

120. Vágási, C.I. The origin of feather holes: A word of caution. J. Avian Biol. 2014, 45, 431-436. [CrossRef]

121. Clusella-Trullas, S.; van Wyk, J.H.; Spotila, J.R. Thermal melanism in ectotherms. J. Therm. Biol. 2007, 32, 235-245. [CrossRef]

122. Bech, C.; Præsteng, K.E. Thermoregulatory use of heat increment of feeding in the tawny owl (Strix. aluco). J. Therm. Biol. 2004, 29, 649-654. [CrossRef]

123. Margalida, A.; Negro, J.J.; Galván, I. Melanin-based color variation in the bearded vulture suggests a thermoregulatory function. Comp. Biochem. Physiol. A 2008, 149, 87-91. [CrossRef] [PubMed]

124. Negro, J.J.; Sarasola, J.H.; Fariñas, F.; Zorrilla, I. Function and occurrence of facial flushing in birds. Comp. Biochem. Physiol. A 2006, 143, 78-84. [CrossRef] [PubMed]

125. Bamford, A.J.; Monadjem, A.; Hardy, I.C. Associations of avian facial flushing and skin colouration with agonistic interaction outcomes. Ethology 2010, 116, 1163-1170. [CrossRef]

126. Koskenpato, K.; Ahola, K.; Karstinen, T.; Karell, P. Is the denser contour feather structure in pale grey than in pheomelanic brown tawny owls Strix aluco an adaptation to cold environments? J. Avian Biol. 2016, 47, 1-6. [CrossRef] 
127. Karell, P.; Ahola, K.; Karstinen, T.; Valkama, J.; Brommer, J.E. Climate change drives microevolution in a wild bird. Nat. Commun. 2011, 2, 208. [CrossRef] [PubMed]

128. Gümüşlü, S.; Sarikçioğlu, S.B.; Sahin, E.; Yargiçoğlu, P.; Ağar, A. Influences of different stress models on the antioxidant status and lipid peroxidation in rat erythrocytes. Free Radic. Res. 2002, 36, 1277-1282. [CrossRef] [PubMed]

129. Caro, T.I.M. The adaptive significance of coloration in mammals. BioScience 2005, 55, 125-136. [CrossRef]

130. Searcy, W.A.; Nowicki, S. The Evolution of Animal Communication: Reliability and Deception in Signaling Systems; Princeton University Press: Princeton, NJ, USA, 2006.

131. Hasson, O. Towards a general theory of biological signaling. J. Theor. Biol. 1997, 185, 139-156. [CrossRef] [PubMed]

132. McGraw, K.J. An update on the honesty of melanin-based color signals in birds. Pigment Cell Melanoma Res. 2008, 21, 133-138. [CrossRef] [PubMed]

133. Guindre-Parker, S.; Love, O.P. Revisiting the condition-dependence of melanin-based plumage. J. Avian Biol. 2014, 45, 29-33. [CrossRef]

134. Zahavi, A. Mate selection-a selection for a handicap. J. Theor. Biol. 1975, 53, 205-214. [CrossRef]

135. Chaine, A.S.; Lyon, B.E. Adaptive plasticity in female mate choice dampens sexual selection on male ornaments in the lark bunting. Science 2008, 319, 459-462. [CrossRef] [PubMed]

136. Galván, I.; Sanz, J.J. The cheek plumage patch is an amplifier of dominance in great tits. Biol. Lett. 2008, 4, 12-15. [CrossRef] [PubMed]

137. Galván, I.; Sanz, J.J. Cheek plumage uniformity as a social status signal in great tits. Ann. Zool. Fenn. 2009, 46, 271-282. [CrossRef]

138. Galván, I. The importance of white on black: Unmelanized plumage proportion predicts display complexity in birds. Behav. Ecol. Sociobiol. 2008, 63, 303-311. [CrossRef]

139. Fargallo, J.A.; Velando, A.; López-Rull, I.; Gañán, N.; Lifshitz, N.; Wakamatsu, K.; Torres, R. Sex-specific phenotypic integration: Endocrine profiles, coloration, and behavior in fledgling boobies. Behav. Ecol. 2014, 25, 76-87. [CrossRef]

140. Galván, I.; Wakamatsu, K.; Camarero, P.R.; Mateo, R.; Alonso-Alvarez, C. Low-quality birds do not display high-quality signals: The cysteine-pheomelanin mechanism of honesty. Evolution 2015, 69, 26-38. [CrossRef] [PubMed]

141. Galván, I.; Bonisoli-Alquati, A.; Jenkinson, S.; Ghanem, G.; Wakamatsu, K.; Mousseau, T.A.; Møller, A.P. Chronic exposure to low-dose radiation at Chernobyl favours adaptation to oxidative stress in birds. Funct. Ecol. 2014, 28, 1387-1403. [CrossRef]

142. Hill, H.Z.; Hill, G.J. UVA, pheomelanin and the carcinogenesis of melanoma. Pigment Cell Res. 2000, 13, 140-144. [CrossRef] [PubMed]

143. Galván, I.; Ghanem, G.; Møller, A.P. Has removal of excess cysteine led to the evolution of pheomelanin? BioEssays 2012, 34, 565-568. [CrossRef] [PubMed]

144. Galván, I.; Møller, A.P. Pheomelanin-based plumage coloration predicts survival rates in birds. Physiol. Biochem. Zool. 2013, 86, 184-192. [CrossRef] [PubMed]

145. Galván, I.; Møller, A.P. Brain size and the expression of pheomelanin-based color in birds. J. Evol. Biol. 2011, 24, 999-1006. [CrossRef] [PubMed]

146. Almasi, B.; Roulin, A.; Jenni-Eiermann, S.; Jenni, L. Parental investment and its sensitivity to corticosterone is linked to melanin-based coloration in barn owls. Horm. Behav. 2008, 54, 217-223. [CrossRef] [PubMed]

(C) 2016 by the authors; licensee MDPI, Basel, Switzerland. This article is an open access article distributed under the terms and conditions of the Creative Commons Attribution (CC-BY) license (http://creativecommons.org/licenses/by/4.0/). 